\title{
STUDENTS BUILDING DIDACTIC EXPERIMENTS AS A TOOL FOR TEACHING UNIT OPERATIONS AND PROCESS CONTROL FOR CHEMISTRY TECHNICIANS
}

\author{
Rodrigo Battistia,*,(®), Graziele V. B. Possentia, Ana Paula Figueiredo and Marcelo Dal Bóa \\ 'Instituto Federal de Educação, Ciência e Tecnologia de Santa Catarina, Campus Criciúma, 88813-600 Criciúma - SC, Brasil
}

Recebido em 20/05/2019; aceito em 22/07/2019; publicado na web em 30/08/2019

\begin{abstract}
The qualified preparation of technician chemistry students who will act directly in the operation and control of industrial chemical plants is a permanent challenge in the teaching-learning process, since such activities require a broad view of the process and a sum of knowledge's areas such as unit operations, instrumentation and industrial process control. An alternative to better understand these chemical engineering subjects within the technician chemistry course is the use of didactic experiments, which aims to provide an approximation of the taught content in the classroom with practical operation in a dynamic way, facilitating the teaching-learning process. In this sense, this work aimed to propose to the students of the technician chemistry course integrated to high school to use their creativity, combined with the technical concepts studied in the classroom, to build didactic experiments of unit operations within the following topics: heat exchanger, adsorption, humidification and drying. The results were evaluated in the form of performance technical data and qualitative questionnaire. Results have evidenced the positive character in the teaching-learning process of the operating principles of the unit operations, besides allowing the students a direct contact with process control and industrial instrumentation.
\end{abstract}

Keywords: didactic experiments; chemistry technicians; unit operations; process control.

\section{INTRODUCTION}

The Federal Institute of Education, Science and Technology of Santa Catarina (IFSC) has the purpose of training and qualifying professionals in the technical and technological vocational education at the basic and higher levels, as well as offering undergraduate and pedagogical training courses, bachelor's degree and postgraduate studies both lato and stricto sensu. For this, the institution operates in different levels and modalities of teaching, offering courses aimed at the education of young people and adults, initial and continuing training, technicians integrated to high school, concomitant and subsequent, undergraduate and postgraduate. The technician chemistry course integrated to high school of IFSC Criciúma campus is a course with a total duration of three years, where the student attends the subjects of regular high school in parallel with the technical disciplines of the professionalizing area, in this case the chemistry. Classes take place full time in the first two years, and only in the morning period in the third year. The students of the technician course in chemistry begin to have contact with disciplines of the area of chemical engineering from the second year, when they study disciplines of Unit Operations I and Industrial Process Control I. In the third year, they finish the technical training attending, in addition to others, the disciplines of Unit Operations II and Industrial Process Control II.

Unit operations are sets of individual physical or chemical steps within an industrial process in which they involve a combination of procedures to achieve the desired transformations of raw materials into a value-added product of any scale. Thus, correctly combined and sequenced they will determine the final product. ${ }^{1}$ These set of unit operations include procedures for mass transfer, heat transfer and momentum transfer, resulting in, therefore, several types of industrial equipments and accessories. ${ }^{2}$ In order to achieve the desired operating conditions safely and efficiently, while meeting the environmental and product quality requirements, instrumentation and process control

*e-mail: rodrigo.battisti@ifsc.edu.br is part of fundamental and complementary science. In large-scale integrated process plants, such as oil refineries or chemical plants, thousands of process variables, such as compositions, temperatures and pressures, are measured and controlled at the same time. The process control systems compare the experimental measurements with the desired values and then adjust the manipulated variables accordingly to achieve the desired objectives. ${ }^{3}$

The discipline of Unit Operations II aims to present the main mechanisms of heat and mass transfer, as well as operational equipment procedures. These processes involve the study of unit operations of heat transfer as: evaporation and condensation, steam generation and heat exchangers; and mass transfer unit operations as: distillation, absorption, adsorption, drying; liquid-liquid extraction and solid-liquid extraction. Acquiring this knowledge, the students will have the aptitude and competence to select equipment for chemical process according to the industrial needs. The discipline of Industrial Processes Control II has as objective to provide to the student the understanding of the working principles of the main organic industrial plants and to appropriate the fundamentals concepts of process control in industrial chemical processes. With this, the students will have aptitude and competence to assist in the control of chemical processes, besides being able to manipulate the measurement and control instruments most commonly used in the chemical industry.

Such contents are often difficult to assimilate in the learning process for most of the secondary students of the technician chemistry course due to the fact that unit operations and their basic principles involved, as well as the control strategies and instrumentation used, are somewhat distant subjects from the daily high school academic life., ${ }^{4,5}$ At the same time, these lessons contents are challenges to the teachers for explaining and discussing in class such diverse and complicated processes due to the level of education. ${ }^{6} \mathrm{New}$ teaching strategies seek to build upon student curriculum progression through skill development, the role of the teacher as a learning guide, active student participation, encouraging self-learning and using smaller groups, allowing for more direct interaction in student-teacher and student-student levels. ${ }^{7,8}$ 
New teaching methodologies such as the problem-based learning, ${ }^{9}$ the autonomous learning, ${ }^{10}$ inverted teaching ${ }^{11}$ and introducing coordination activities among students ${ }^{12}$ are being widely applied in the field of engineering teaching. Despite this, case studies involving secondary-level technician students are still scarce. Thus, the construction of didactic experiments, as an active teaching-learning methodology, is a way to allow an approximation of the industrial routine to the technician chemistry students, especially of industrial equipments and processes, demystifying and concretizing the theoretical approach discussed in class more comprehensively and visualizing different types of equipment, as well as their dimensions, characteristics and practical applications. ${ }^{13-16}$ An example of success has been described by Vega et al. ${ }^{17}$ where students developed tasks related to process design, selection of optimal alternatives, decision making, basic engineering design, and materials procurement management, which concluded with the assembly and start-up of a laboratory-scale distillation unit. The methodology allowed working all the competences with high participation and motivation of the students, being able to be considered a useful and attractive tool to be incorporated in experimental disciplines related to chemistry. Another successful example was proposed by Young et al., ${ }^{18}$ where students were asked to devise and carry out their own experiments to evaluate the performance characteristics of a particular unit operation and associated equipments, to critically analyze the results of the experiments and to properly report such results. This approach, called "hands-on", provided a dramatically increasing in the students' learning. This deeper understanding was evident in better student performance in the assessment tasks such as the laboratory proposal, participation and reports.

In this sense, the objective of this work, based on this active teaching-learning methodology, was to propose to the students of the technician chemistry course integrated to high school, the design, planning, construction and evaluation of the performance of didactic experiments of the following subjects related to unit operations: heat exchanger, adsorption, humidification and drying. With this, it was intended to provide students with a technical-industrial vision, with direct application of the theoretical knowledge of these unit operations and their instrumentation and control. Considering that most of the technician courses do not have enough theoretical bases in relation to the mathematical concepts of engineering, when it comes to practical knowledge, this can greatly help in the formation of the future chemistry technician professional, giving even more security for their work in the process industry.

\section{METHODOLOGY}

This work is a result of a one-year duration institutional didacticpedagogical project involving the professors of the curricular units related to chemical engineering subjects, namely, Industrial Process Control II and Unit Operations II. The methodology was applied on the third year class of the technician chemistry course integrated to high school of IFSC Criciúma campus. The class consisted of 32 students aged between 16 and 18 years. The students were systematically monitored throughout the school year from the partial delivery of results to teachers. In addition, every 15 days approximately, spaces for discussion were provided during classes so that the students could work with their groups in the project development. Teachers were in class available to answer questions and explanations. The extra-class attendance was always done in the afternoon period, with prior scheduling with the respective teacher. Chemistry teaching and research laboratories were available for the students to work on their projects, always accompanied by a teacher or a laboratory technician. The criteria adopted for selecting the didactic experiment were based on the technical feasibility of executing the project with the available resources limit. The selected equipment would still need to contemplate heat or/and mass transfer phenomena, which are part of the scope of the Unit Operations II discipline. The activities of this work can be divided into five main steps, as shown in Figure 1.

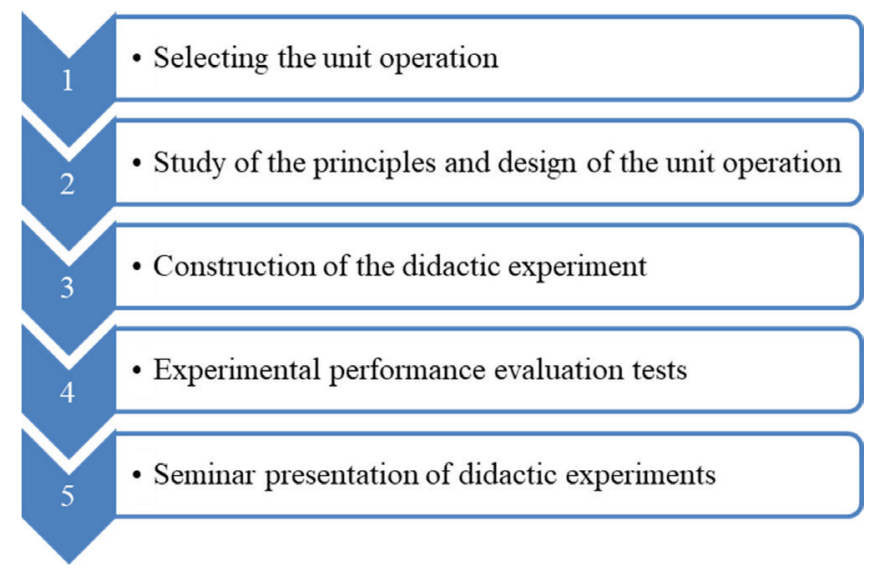

Figure 1. Steps in the development of the didactic experiments

\section{Course learning objectives}

The learning objectives of the discipline of Unit Operations II of the course are explicitly communicated to the students as follows:

- To study the industrial mechanisms used for the production and transport of heat;

- Selecting equipments for each stage of the process according to the industrial needs presented;

- Knowing aspects of environment preservation, impacts of industrial processes and waste treatment;

- Learning how to operate in order to demonstrate in practice the concepts and methods;

- Identifying problems related to operational maintenance needs of equipment parts;

- Knowing the basic economics concepts applied to the chemical industry.

For the discipline of Industrial Process Control II, the specific learning objectives are:

- Knowing the equipment and reactors used in chemical processes;

- Recognizing the applicability and importance of the basic knowledge acquired to understand the evolution and functioning of the industrial chemical park;

- Identifying and controlling industrial chemical process equipment;

- Auxiliary in the control of industrial chemical processes;

- Recognizing the possible reuse of residues from chemical plants;

- Identifying the main unit operations applied in industrial chemical processes;

- To identify, from the understanding of a chemical process, the direct correspondence between process flowchart and control panel;

- To know fundamental concepts of the process control in the scope of industrial automation;

- Developing the ability to identify an industrial controller;

- Learning how to manipulate process control instruments;

- Identifying the variables of a process in a chemical transformation industry and its respective controlling strategy. 


\section{Group assignments}

Initially, the students were divided into four groups and, together, they selected the unit operation to be studied, previously determined by the teacher, namely: heat exchanger; drying; adsorption; humidification. Later, the groups investigated the theoretical bases of the selected unit operation, in order to understand the involved principles, as well as the applicable measurement and control instruments. During the classes, and also in extraclass moments, the students met and discussed with the help of the teachers, how they would develop and create the didactic experiments representative of each unit operation.

\section{Project financing and construction}

After designing the unit operation project, and having knowledge of the process variables that will be measured and controlled (temperature, pressure, concentration, humidity, etc.), the students constructed the didactic experiments with the materials purchased with a budget coming from a institutional didactic-pedagogical project associated, promoted by the Federal Institute of Education, Science and Technology of Santa Catarina, in the amount of \$ 200 per group.

\section{Data collection and performance analysis}

Each group was responsible for experimental tests to evaluate the performance of the didactic prototypes, modifying the raw materials, inputs and/or process variables, in order to analyze the effects of these variables in the unit operation efficiency. The process conditions tested on the equipment were based on the feasible ranges of operation, such as maximum temperature reached by the heaters and maximum flow of installed hoses. As for the types of raw materials used for drying and adsorption, materials commonly found in local industries and region were used.

\section{Assessment}

As a conclusion part of the project, the groups delivered a final written work and held a round of oral presentations, with the purpose of explaining the didactic experiments to a committee composed of one of the guiding teachers and one external member. At this time we discussed the concepts learned as well as shared the experiences and challenges encountered throughout the development of the project.

\section{EXPERIMENTAL WORK}

\section{Heat exchanger}

First, a research was carried out to determine the possibilities of the heat exchanger model, thus choosing the serpentine heat exchanger, in which there is an external structure (tube or box) and a metal coil is installed inside. This model was chosen because the internal structure (thermal exchange area) is easier to mold and install. For the external shell was chosen the glass, because of the low coefficient of thermal exchange and for being transparent, improving its didactic aspect. It was determined, together with the professors of the disciplines that the length of the glass box would be $50 \mathrm{~cm}$ and its base would be a square of $10 \mathrm{~cm}$ edge. With these data it was performed the calculations to determine the number of turns of the serpentine and the radius, allowing an effective thermal exchange between the fluids. The temperature sensors were installed in the hose that supplies the heat exchanger with cold water, in the hose through which the water passes after the heat exchange process, and in the hose where the water from the thermostatic bath returns to the equipment. The flow sensors were installed before the temperature sensor on the hose where the water from the thermostatic bath returns to the equipment and on the hose that supplies the heat exchanger with cold water.

\section{Adsorption}

Initially, a wooden support was built, in which three acrylic tubes with $5.0 \mathrm{~cm}$ in diameter were placed, two with $50 \mathrm{~cm}$ in length and one with $100 \mathrm{~cm}$ in length. The selected adsorbent materials (rice hull and corn straw) were packed in the tubes, characterizing a fixed bed adsorption column. The process was started by pumping the adsorbate, methylene blue, with a concentration of $10 \mathrm{mg} \mathrm{L}^{-1}$, into the column with the aid of a peristaltic pump. Subsequently, the solution went through the column with fixed adsorbent filling and was collected, according to the established time intervals, at the top of the column. After collection, the sample had its absorbance measured. To prepare the calibration curve solutions of known concentration were prepared, which had their absorbance measured in the spectrophotometer.

\section{Humidification}

The humidification tower was built using a $6.0 \mathrm{~mm}$ thick glass, and dimensions of $80 \mathrm{~cm}$ high with a square base of $20 \mathrm{~cm} \times 20 \mathrm{~cm}$. A portable compressor, available at the institution, was used to inject compressed air with controlled flow. An electric resistance was used to heat the water. The temperature and humidity sensors with display were used to allow the reading of these process variables. In order to optimize the use of water, a reflux was implanted, which was done with the help of a domestic aquarium pump. The reservoir in which the reflux water is located is next to the glass tower, using gravity to flow the water from the tower to the reservoir.

To carry out the process control, an Arduino DUE was used which was programmed to measure the humidity and to control the temperature, based on the data of its respective sensors. The sensor was programmed to measure the bucket temperature and transmit the information to the Arduino. This, in turn, turns the resistance on or off to maintain the inlet water temperature in the range of $40^{\circ} \mathrm{C}$ to $50^{\circ} \mathrm{C}$. The Arduino was programmed so that it received the information from the humidity sensor and converted it to a real value, which is shown on the display as humidity C (top) and humidity B (base) of the humidification tower. In this context, the humidity of the top is related to the exit humidity of the tower and the humidity of the base to the relative humidity of the environment. Still with regard to the Arduino, this will make the pump to remain in operation. With the programming part ready, the control part was mounted, fixing the devices to the designated places. With the entire equipment mounted, the tests of the humidification tower were performed.

\section{Drying}

Relative humidity, air velocity and air temperature were selected as parameters to be analyzed by the dryer unit operation. The dryer structure, at the suggestion of the teachers of the disciplines, was divided into two separate parts, one part containing the balance (load cell) and one part containing the fan, so that the motor vibrations had no influence on the values measured on the scale. The section containing the motor contained also the electrical resistance that provides heat to the system. The section that includes the load cell, for didactic purposes was made of glass, so that students can see the sample during drying. The division between the two parts 
characterizes a bottleneck. A digital anemometer was used to measure wind speed. To assess the relative humidity of the air, the use of sensors was first considered, but as a suggestion of the teachers a system of dry bulb and wet bulb thermometers were also developed by the students themselves.

\section{RESULTS AND DISCUSSION}

The experimental prototypes of the didactic experiments constructed by the four groups of the technician chemistry students' class with the unit operations selected can be visualized in Figure 2. (a)

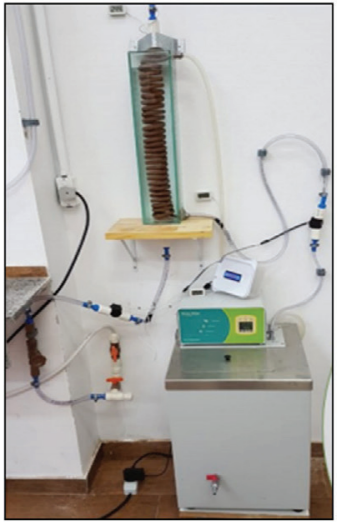

(c)

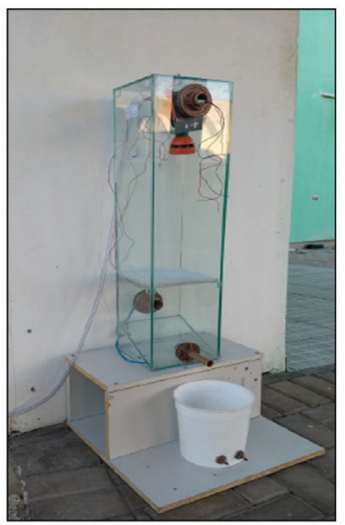

(b)

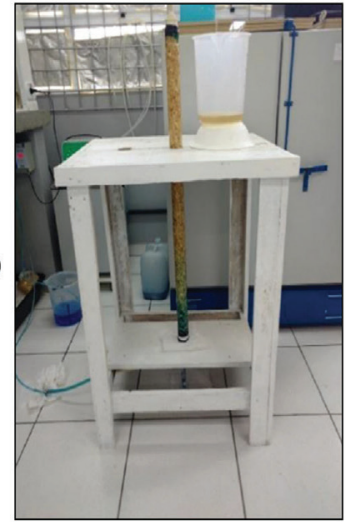

(d)

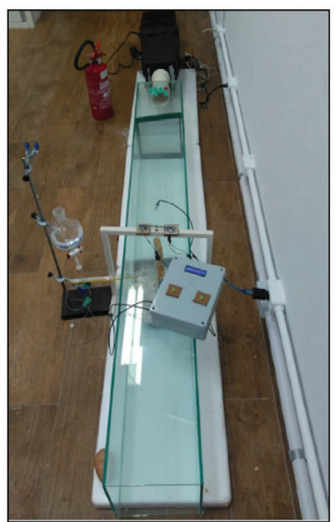

Figure 2. Images of didactic experiments constructed: (a) heat exchanger; (b) adsorption column; (c) humidification tower; and (d) tray dryer

\section{Heat exchanger}

By putting in practice the knowledge acquired in the subjects of Processes and Industrial Control II and Unit Operations II of the technician chemistry course integrated to high school, it was possible for the students to develop the assembly of the didactic experiment of a heat exchanger. Heat exchangers are widely used equipment in the chemical industry and constitute an extremely important unit operation. Although the operation and control of these equipments are relatively simple, their analysis and design are relatively complex for high school students. ${ }^{19}$ Figure 2 (a) shows the image of the prototype equipment constructed, as well as all the instrumentation and control that was developed by the students, for controlling the flow rate and the temperature of the inlet water to the heat exchanger (hot and cold).

After completing the heat exchanger assembly, the equipment performance analysis tests were performed. In order to carry out the experiments, the thermostatic bath and the flow rate sensors system were connected to the outlet next to the heat exchanger. The bath was connected, the sensors were opened, the register was opened and the desired flow rate was controlled, from the valve and the flow sensor.
Initially, the bath was programmed to warm until $40{ }^{\circ} \mathrm{C}$. When the process reached the steady state, the data provided by the temperature sensors were recorded on a spreadsheet and the bath temperature was then raised respectively to $50{ }^{\circ} \mathrm{C}$ and $60{ }^{\circ} \mathrm{C}$ proceeding in the same way. Subsequently, the flow rate was changed and the temperature recording steps redone as described above.

With the results of temperature and flow rate at the inlet and outlet of the heat exchanger, it was proceeded to perform the heat exchange efficiency calculations. By averaging the hot and cold heat values of the countercurrent and concurrent flows, it was possible to compare the amount of heat exchanged in each stream. In the countercurrent flow, this average was $1011.33 \mathrm{~J} \mathrm{~s}^{-1}$, while in the concurrent flow this value was $800.23 \mathrm{~J} \mathrm{~s}^{-1}$. In a basic analysis, it can be said that for the heat exchanger constructed, within the range in which it was studied, the countercurrent flow was the one that obtained the greatest heat exchange between the fluids. As the flow of cold water and/or hot water inlet temperature increases, the heat exchange in the equipment also increases, which reflects in a larger overall coefficient, reaching the maximum values of $2810.5 \mathrm{~W} \mathrm{~m}^{-2}{ }^{\circ} \mathrm{C}^{-1}$ for countercurrent flow, and $1374.0 \mathrm{~W} \mathrm{~m}^{-2}{ }^{\circ} \mathrm{C}^{-1}$ for the concurrent flow. In Figure 3 the values of the overall heat transfer coefficients realized in the countercurrent flow condition can be observed, by varying two flow rates for each hot water inlet (serpentine) temperature.

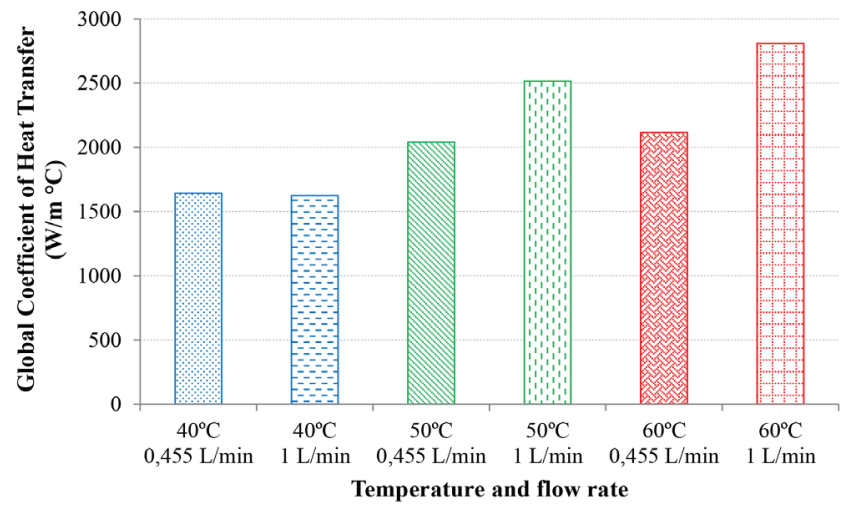

Figure 3. Overall heat transfer coefficients in countercurrent flow condition

In Figure 4 it is possible to observe the values of the six experimental tests performed in the heat exchanger constructed for the concurrent flow condition, also varying two flows for each hot water (serpentine) inlet temperature.

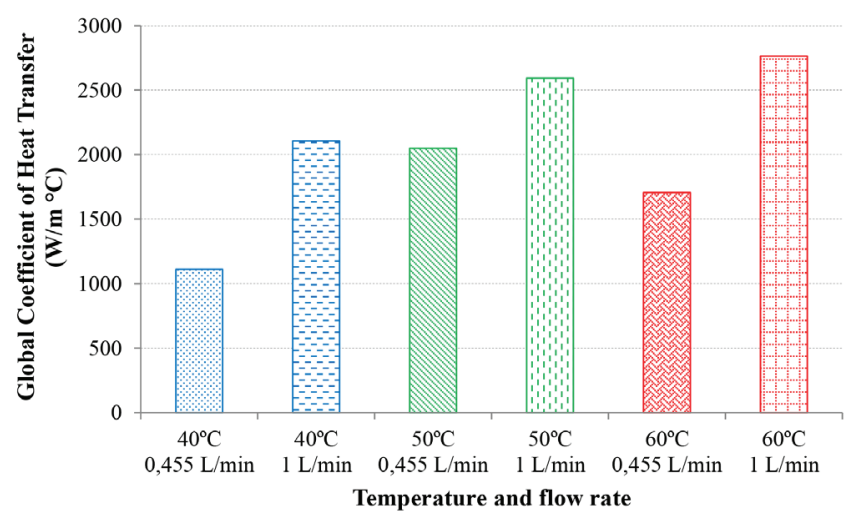

Figure 4. Overall heat transfer coefficients in concurrent flow condition

\section{Adsorption column}

Adsorption is a technique widely used to remove contaminants from wastewater, especially at low concentrations. Different 
adsorbents have already been developed from natural materials available such as activated carbon, pine bark, coal, banana bark, bituminous sands, modified rice hulls, zeolites, among many others. ${ }^{20}$ Figure 2 (b) shows an image of the adsorption column constructed, as well as all the instrumentation and control that was developed by the students, to control the effluent flow (dye solution) and the absorbance, which was made with the aid of a spectrophotometer UV-Vis. The performance tests of the didactic experimental prototype of the adsorption unit operation were performed with two low cost adsorbents, corn straw and rice husk, which are agroindustrial residues available in abundance in the region where the IFSC Campus Criciúma is located. The Figure 5 shows the behavior of the concentration for the two adsorbents tested by reading the absorbance of the methylene blue dye solution being made after passing through the entire column filling.

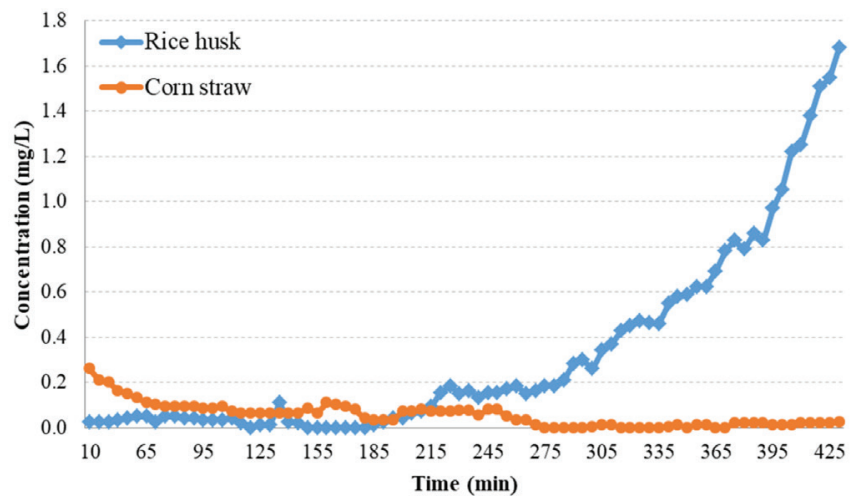

Figure 5. Comparison between the two adsorbents used in the adsorption experiment

Analyzing Figure 5, it can be seen that corn straw kept its adsorption capacity high for longer than rice husk, but this can be explained by the difference between the masses used, since the amount of rice husk used, which was $36.8 \mathrm{~g}$, equivalent to $20 \%$ of the mass of corn straw used, which was $184 \mathrm{~g}$. It is also possible to notice that from the time of $300 \mathrm{~min}$ the column with rice husk began to saturate, losing the adsorption capacity of the methylene blue dye, when the solution at the exit of the tower happens to be with concentration similar to that of the entrance.

\section{Humidification tower}

The humidification unit operation is present not only in the industries, but also in our daily life. The operation of a humidification tower consists of the entrance of water (at the top) and air (at the bottom) in a column, promoting the contact between them in a countercurrent direction. In this way, the water humidifies the air, which in turn leaves at the top of the equipment with a humidity greater than that of the inlet. ${ }^{21}$ Figure 2 (c) shows the image of the built equipment as well as all the instrumentation and control that was developed by the students to measure the humidity of the air before and after the entrance of the tower. After assembly, a total of six experiments were performed in the humidification tower, with and without the presence of filling, with results being described in Table 1.

The performance tests showed that there was no significant difference between the column with or without packing, and there was an average difference of $40 \%$ of humidity between the intake and exhaust air, confirming the efficient operation of the equipment. In the performed tests it can be noted that they all remained stabilized at $99.9 \%$ humidity in three minutes, and then this moisture rapidly plummeted to an average of $58 \%$. This may have happened because there is a greater intake of water than air, causing the air to become saturated with water rapidly. Another factor that may have caused this was the possible location of the sensor. This one was installed in the air outlet of the tower in a location very close to air flow interferences. This was one of the problems raised by the group students for future improvements in the didactic equipment.

\section{Tray dryer}

In the tray dryer, which was developed to represent the drying unit operation, students can study aspects of fluid mechanics, surface chemistry, solid structure and mass and heat transfer associated with the process. Drying, which is the final removal of water or other volatile liquid from a moist solid, is performed before packaging some products to improve their shelf life and reduce transportation costs by reducing the weight of a product. ${ }^{22}$ Figure 2 (d) shows the image of the built didactic equipment, as well as all the instrumentation and control that was developed by the students to control the mass loss of the material, air flow rate in the dryer and temperature.

For the preparation of drying tests in the built equipment, firstly some materials were selected according to the teachers' instructions, being these: a vegetable product (wood), a food (apple) and a ceramic product (brick). For the tests involving the brick and wood, the samples were directly moistened, without any previous procedure. In the drying of the apple, it was cut into slices before wetting, for a better drying efficiency. The wetting was done by immersing the materials individually in water for about $10 \mathrm{~min}$. The mass was measured before and after the wetting. The materials were placed in the equipment tray dryer, having their mass measured by the load cell. Drying started when the heater and motor were turned on, making hot air to enter the drying tunnel.

As the drying time is different from one material to the other, the end of drying was determined by mass variation parameters. The mass of the materials was analyzed at 5 min intervals, and drying was stopped as soon as the mass was stabilized by two consecutive measurements after reaching the dry mass of the material. It is important to note that some materials have moisture naturally even before wetting, so drying cannot be interrupted when the mass equals the dry mass, only after, even at low, the mass stabilizes. Figure 6

Table 1. Test results in built-up humidification tower

\begin{tabular}{|c|c|c|c|c|c|c|}
\hline & \multicolumn{3}{|c|}{ Without packing } & \multicolumn{3}{|c|}{ With packing } \\
\hline & Test 1 & Test 2 & Test 3 & Test 4 & Test 5 & Test 6 \\
\hline Initial top moisture (C) & $57.9 \%$ & $59.4 \%$ & $59.2 \%$ & $57.6 \%$ & $59.9 \%$ & $55.1 \%$ \\
\hline Final top moisture (C) & $99.9 \%$ & $99.9 \%$ & $99.9 \%$ & $99.9 \%$ & $99.9 \%$ & $99.9 \%$ \\
\hline Initial bottoms moisture (B) & $36.1 \%$ & $37.0 \%$ & $35.4 \%$ & $37.1 \%$ & $38.0 \%$ & $32.5 \%$ \\
\hline Final bottoms moisture (B) & $35.0 \%$ & $37.0 \%$ & $34.8 \%$ & $38.0 \%$ & $37.8 \%$ & $31.5 \%$ \\
\hline Temperature & $50^{\circ} \mathrm{C}$ & $48^{\circ} \mathrm{C}$ & $49^{\circ} \mathrm{C}$ & $48^{\circ} \mathrm{C}$ & $47^{\circ} \mathrm{C}$ & $50^{\circ} \mathrm{C}$ \\
\hline
\end{tabular}


shows the experimental drying curves of the three materials tested in the tray dryer built by the students.

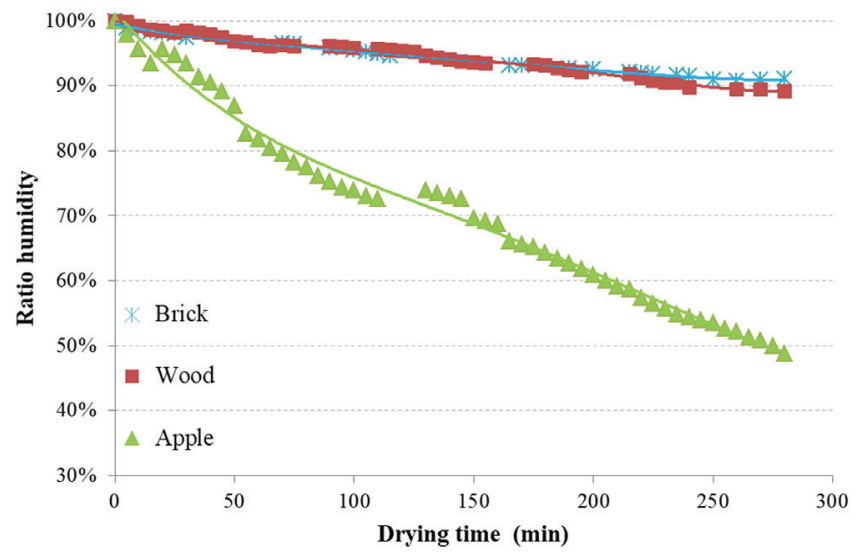

Figure 6. Drying curves for the three materials tested in the tray dryer constructed

Analyzing the obtained mass loss curves of the three materials, it is possible to observe that the apple drying test obtained more effective results, having a curve with greater drying efficiency in relation to the others. For this analysis of these graphs, we must consider that several variables interfered in the drying process, such as variation of air flow rate and accuracy of the digital balance due to tray balance and equipment calibration. In general, it is concluded that the drying process of different materials using the assembled equipment requires certain care with the load cells and the movement of the balance to ensure a better accuracy of the measured masses. In addition, the materials used should be positioned in specific ways on the slurry, ensuring a larger area of contact. For tests with greater accuracy, it would be necessary to calibrate the equipment as a whole and a more adequate environment to carry out the experiment.

\section{Learning assessment}

Regarding to aspects of learning assessment, teachers have considered the grade of the project group to be part of the individually students' final grade. With this, it was noticed that there was a positive increase in the averages and consequently in the approvals of the disciplines. After the final repeat examination, required by the institution, there was no record of any disapproval, both in Unit Operations II discipline and in Industrial Process and Control II discipline. It has not been possible yet to make a comparison with another previous class, since in 2018 it was the first graduated technician chemistry class in IFSC Criciúma campus.

\section{Student evaluations}

Every semester the students carry out evaluations of the disciplines, according to the institutional policy. These assessments are generally related to the overall quality of the course. ${ }^{18}$ In addition to the evaluation, a survey was also carried out with specific questions related to the learning aspects directed to this project. The great majority of the students liked the methodology, considering the construction of didactic experiments a relevant challenge for the learning of unit operations and chemical process control. Table 2 shows the number of responses for each search statement indicating "totally agree" to "totally disagree". In total, 20 students responded to this survey. The research questions are related to the aspects of learning and application of the methodology. Figure 7 shows the percentage of student groups that responded to each search statement. The research demonstrated a positive effect on students' perception of learning. For all statements, the proportion of student groups that agree with the research statements is much larger than the proportion of students disagreeing. In terms of total percent of the questionnaire responses, $55 \%$ were "Totally agree", $29 \%$ "Agree", $10.5 \%$ "Neutral", $5 \%$ "Disagree", and $0.5 \%$ "Totally disagree", which shows the majority acceptance of the methodology.

The students were also invited to make other written comments in the survey conducted at the end of the project. There have been many comments on the optional response part of the survey that reflects the very understanding and learning of the group of students in this class. These were generally positive and they are summarized below in critical order from more positive to more negative.

"It was a wonderful experience, I learned things that I will take to life and also the contact with other courses was enriching. I hope that other classes could have this opportunity."

"It was extremely satisfying to see the tower running, to see that every detail made a difference in the end! You, teachers, were too helpful, thanks for the experience."

Table 2. Qualitative evaluation of the didactic-pedagogical methodology

\begin{tabular}{|c|c|c|c|c|c|}
\hline Questions & Totally agree & Agree & Neutral & Disagree & Totally disagree \\
\hline $\begin{array}{l}\text { Q1. Were the objectives and justifications of the } \\
\text { proposal of the didactic experiment clear? }\end{array}$ & 6 & 7 & 4 & 3 & 0 \\
\hline $\begin{array}{l}\text { Q2. Have the safety conditions always been } \\
\text { provided? }\end{array}$ & 9 & 8 & 3 & 0 & 0 \\
\hline $\begin{array}{l}\text { Q3. Was the budget available to purchase materials } \\
\text { sufficient? }\end{array}$ & 11 & 4 & 0 & 5 & 0 \\
\hline $\begin{array}{l}\text { Q4. Did your level of understanding on the subject } \\
\text { after doing the work increase? }\end{array}$ & 13 & 4 & 3 & 0 & 0 \\
\hline $\begin{array}{l}\text { Q5. Did the teachers have availability and help with } \\
\text { enthusiasm? }\end{array}$ & 14 & 5 & 1 & 0 & 0 \\
\hline $\begin{array}{l}\text { Q6. Did you learn the practical use of the equipment } \\
\text { by creating the didactic prototype? }\end{array}$ & 12 & 8 & 0 & 0 & 0 \\
\hline $\begin{array}{l}\text { Q7. Did you see the connection between theory } \\
\text { learned in class and practice? }\end{array}$ & 10 & 5 & 4 & 1 & 0 \\
\hline $\begin{array}{l}\text { Q8. Would you be able to handle an equal unit } \\
\text { operation in an industry? }\end{array}$ & 9 & 6 & 5 & 0 & 0 \\
\hline Q9. Was it an intellectually stimulating challenge? & 11 & 7 & 1 & 0 & 1 \\
\hline $\begin{array}{l}\text { Q10. Do you think this methodology would be } \\
\text { applicable to other classes in the future? }\end{array}$ & 15 & 4 & 0 & 1 & 0 \\
\hline
\end{tabular}




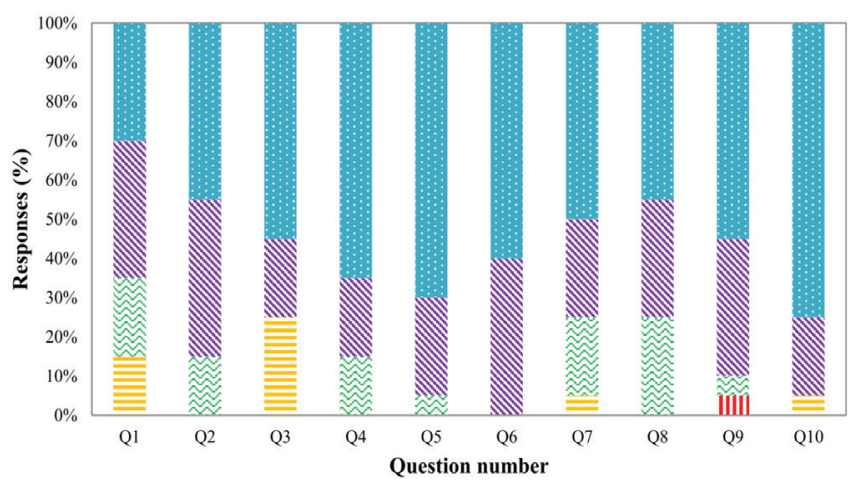

I Totally disagree - Disagree $\approx$ Neutral $\quad$ Agree $\approx$ Totally agree

Figure 7. Respondents' approval for each of the ten survey questions

"Overall, it was a good experience, thank you."

"I think it was a wonderful idea, but it should have a public notice. Something that could guide the students. Intermediate evaluations also would be nice and more year-round encouragement, maybe propose a way to organize time with monthly goals. The groups definitely should be smaller. The groups could be "patronized" with a teacher or technician."

"I admit it was a difficult project to develop, not only because of the content itself, but because of the requirement of prolonged attention. On the other hand, it promoted greater learning of the content. Overall, the proposed development of a humidification tower was a challenge that brought many experiences that could not be passed on in the classroom."

"It would be interesting to elaborate an "assembly script" with a kind of schedule to be followed to avoid problems in the team time planning."

It is observed that most of the negative reviews made by the students are due to the lack of a "script" or a "guide" that contains all the step-bystep guidelines to be executed throughout the project period. Actually, there is not an instruction guide yet. Certainly this point raised will be taken into consideration by teachers to be elaborated in the future with other classes. On the other hand, the very nature of the practical do-it-yourself methodology was one of the motivations that led to the development of this work with the intention of awakening students' autonomy. Finally, a relation between the advantages and disadvantages observed by the students and by the teachers is summarized, showing different visions of the teaching-learning methodology. For the students, the main advantages were the possibility of contact with other areas of knowledge and learning beyond technical contents; as disadvantages, they questioned the absence of a detailed step-by-step guide of what to do each stage, and the need for prolonged dedication even in extra-class periods, in which teachers also agree to be a disadvantage that can be improved in the future. However, for the teachers, the main advantage of this teaching-learning methodology provided was the visible improvement in the maturity of the students, especially because they were in secondary technical level, since they had to develop autonomy in the search for solving real problems. With this, the great contribution is certainly training more prepared technicians for professional real situations in chemical process industries.

\section{CONCLUSIONS}

The construction of didactic experiments of unit operations and their respective control and instrumentation meshes enabled students the direct contact with multidisciplinary areas, such as creative design, budgeting, materials purchase and risk management. This didactic tool proved to be adequate to carry out experimental teaching activities for the technician chemistry course, with little project design calculation load. The success of the methodology was based on the previous planning work carried out by the teachers of the area. The application of this active teaching-learning strategy in the related subjects to chemical engineering proposed for students of the technician chemistry course integrated to high school satisfactorily fulfilled the previous objectives set by encouraging aspects such as autonomous learning, competencybased learning and the role of the teacher as a mentor of learning in the technical areas. The students' evaluation evidenced the positive character in the process of learning the principles of the unit operations, besides allowing the students also contact with the part of processes control and instrumentation, since they installed sensors, valves, meters and looked for strategies to control the didactic experiments built, contributing to the whole with the training of technicians prepared for real situations in chemical industries. The students demonstrate good acceptance with the proposed methodology, which allowed generating an excellent work environment with which it has been possible to fulfill all the tasks and to overcome the problems associated with the teaching-learning process.

\section{ACKNOWLEDGMENTS}

The authors are thankful to Federal Institute of Education, Science and Technology of Santa Catarina (IFSC) for the financial support and structure for the development of this work.

\section{REFERENCES}

1. Cremasco, M. A.; Operações Unitárias Em Sistemas Particulados e Fluidomecânicos, 2ª ed., Edgard Blucher: Campinas, 2012.

2. Foust, A. S.; Wenzel, L. A.; Clump, C. W.; Maus, L.; Andersen, L. B.; Principles of Unit Operations, $2^{\text {nd }}$ ed., Wiley: India, 2008.

3. Seborg, D. E.; Mellichamp, D. A.; Edgar, T. F.; Doyle, F. J.; Process Dynamics and Control, $4^{\text {th }}$ ed., John Wiley \& Sons: New Jersey, 2010.

4. Silva, J. M. A. de P.; Quim. Nova 2001, 24, 135.

5. Matsumoto, L. T. J.; Kuwabara, I. H.; Quim. Nova 2005, 28, 350.

6. Silva, F. C.; Sobreira, H. de A.; Anais do $21^{\circ}$ Congresso Brasileiro de Engenharia Química, Fortaleza, Brasil, 2016.

7. Vega, F.; Navarrete, B.; Educ. Chem. Eng. 2018, 26, 30.

8. Croker, K.; Andersson, H.; Lush, D.; Prince, r.; Gomez, S.; Biosci. Educ. 2010, $16,1$.

9. Branda, L. A.; Educ. Médica 2009, 12, 11.

10. Palacios, M. C.; Borrero, F. V.; Nilsson, S. L.; Arenas, C. G.; Arenas, L. F. V.; Leiva, C.; @ tic Revista d'Innovació Educativa 2014, 97.

11. Christiansen, M. A.; J. Chem. Educ. 2014, 91, 1845.

12. Bogumil, F. T.; Abad, F.; Form Univ. 2008, 1, 13.

13. Narang, A.; Ben-zvi, A.; Afacan, A.; Sharp, D.; Shah, S. L.; Huang, B.; Educ. Chem. Eng. 2012, 7, 187.

14. Penteado, J. C. P.; Magalhães, D.; Masini, J. C.; Quim. Nova 2008, 31, 2190.

15. Rosini, F.; Nascentes, C. C.; Nóbrega, J. A.; Quim. Nova 2004, 27, 1012.

16. Díaz-Lobo, M.; Fernández-Novell, J. M.; Int. J. Adv. Res. Chem. Sci. 2015, 2, 41 .

17. Vega. F.; Portillo, E.; Cano, M.; Form. Univ. 2014, 7, 13.

18. Young, B. R.; Yarranton, H. W.; Bellehumeur, C. T.; Svrcek, W. Y.; Educ. Chem. Eng. 2006, 1, 16.

19. Cartaxo, S. J. M.; Fernandes, F. A. N.; Comput. Appl. Eng. Educ. 2010, $18,193$.

20. Kumar, A.; Sahu, O.; World J. Chem. Educ. 2013, 1, 17.

21. Xu, Z.; Xiao, Y.; Wang, Y.; Appl. Therm. Eng. 2007, 27, 2549.

22. Hossain, S. M. Z.; Mansour, N.; Sultana, N.; Educ. Chem. Eng. 2017, 18,35 . 